\title{
Gender Stereotypes Stem From the Distribution of Women and Men Into Social Roles
}

\author{
Alice H. Eagly and Valerie J. Steffen \\ Purdue University
}

\begin{abstract}
According to stereotypic beliefs about the sexes, women are more communal (selfless and concerned with others) and less agentic (self-assertive and motivated to master) than men. These beliefs were hypothesized to stem from perceivers' observations of women and men in differing social roles: (a) Women are more likely than men to hold positions of lower status and authority, and (b) women are more likely than men to be homemakers and are less likely to be employed in the paid work force. Experiments 1 and 2 failed to support the hypothesis that observed sex differences in status underlie belief in female communal qualities and male agentic qualities. Experiment 3 supported the hypothesis that observed sex differences in distribution into homemaker and employee occupational roles account for these beliefs. In this experiment, subjects perceived the average woman and man stereotypically. Female and male homemakers were perceived as high in communion and low in agency. Female and male employees were perceived as low in communion and high in agency, although female employees were perceived as even more agentic than their male counterparts. Experiments 4 and 5 examined perceptions that might account for the belief that employed women are especially agentic: (a) A double burden of employment plus family responsibilities did not account for this belief, and (b) freedom of choice about being employed accounted for it reasonably well.
\end{abstract}

Gender stereotypes, like other social stereotypes, reflect perceivers' observations of what people do in daily life. If perceivers often observe a particular group of people engaging in a particular activity, they are likely to believe that the abilities and personality attributes required to carry out that activity are typical of that group of people. For example, if perceivers consistently observe women caring for chil-

The research reported in this article was supported by National Science Foundation Grants BNS-7711671, BNS7924471, and BNS-8023311. A preliminary report was presented at the meetings of the Midwestern Psychological Association, May 1982, and the American Psychological Association, August 1982.

The authors thank Wendy Wood for help with the design and statistical analyses of Experiment 1; Vathsala Venugopalan for help with the statistical analyses of Experiments 1 and 2; and Barry Brumer, Deborah Rugs, Jan Schafer, Erik Bronner, and Gail Winbury for assistance in administering materials to subjects. The authors also thank Shelly Chaiken, Kay Deaux, Chester Insko, Dafna Izraeli, Laurie Lewis, Myron Rothbart, Wendy Wood, and two anonymous reviewers for their comments on a draft of the article.

Requests for reprints should be sent to Alice H. Eagly, Department of Psychological Sciences, Purdue University, West Lafayette, Indiana 47907. dren, they are likely to believe that characteristics thought to be necessary for child care, such as nurturance and warmth, are typical of women. Because most of people's activities are determined by their various social roles, stereotypes about groups of people should reflect the distribution of these groups into social roles in a society. Furthermore, certain stereotypes may reflect the distribution of groups into broader aspects of social structure such as social class. For example, beliefs about racial differences may be based at least in part on observations that racial groups differ in social class (Feldman, 1972; Smedley \& Bayton, 1978; Triandis, 1977).

In applying this social structural analysis to people's beliefs about gender, we faced two issues: (a) What is the content of stereotypes about women and men? (b) What are the major differences in the ways that women and men are distributed into social roles? Concerning content, we decided to restrict our focus to the beliefs about gender that, by virtue of the frequency with which they have been documented by research and amplified in theoretical discussions, appear to be most important. 
These beliefs concern communal and agentic personal qualities: Perceivers generally assume that men are oriented toward agentic goals and women toward communal goals (e.g., Bem, 1974; Block, 1973; Broverman, Vogel, Broverman, Clarkson, \& Rosenkrantz, 1972; Spence \& Helmreich, 1978). Following Bakan's (1966) discussion of this distinction, agentic qualities are manifested by self-assertion, self-expansion, and the urge to master, whereas communal qualities are manifested by selflessness, concern with others, and a desire to be at one with others. This distinction has been accorded considerable importance in theoretical discussions of gender (Bakan, 1966; Parsons, 1955) and in the development of measures of sex-typed and androgynous personalities (e.g., Bem, 1974; Spence \& Helmreich, 1978). Furthermore, these beliefs about gender appear to be cross-culturally general (Williams \& Best, 1982).

To examine why women are perceived as communal and men as agentic, we considered two major differences in the distribution of females and males into social roles. The first of these differences is that women are more likely than men to hold positions at low levels in hierarchies of status and authority and are less likely to hold higher level positions. The second difference is that women are more likely than men to be homemakers and are less likely to be employed in the paid work force.

Given the pervasiveness in natural settings of sex differences in status, it seems plausible that gender stereotypes stem from the tendency of perceivers to observe women in lower status roles than men. Such observations would be made in organizational settings in which the positions held by men tend to be higher in status and authority than the positions held by women (e.g., Brown, 1979; England, 1979; Kanter, 1977; Mennerick, 1975). Also, in family settings husbands tend to have an overall power and status advantage over wives (Blood \& Wolfe, 1960; Gillespie, 1971; Scanzoni, 1982). Such differences in the status of men's and women's roles may be determining factors in beliefs about gender.

Another reason for examining status differences is that recent research by Eagly and Wood (1982) demonstrated that the stereotypic beliefs that women are more easily influenced than are men and that men exert influence more easily than do women (e.g., Broverman et al., 1972; Spence \& Helmreich, 1978; Taylor, Fiske, Etcoff, \& Ruderman, 1978) stem from perceivers' inferences that (a) women occupy lower status positions than men and (b) the lower an individual's status relative to other persons, the more that individual yields to their influence. To extend this analysis to the communal and agentic aspects of gender stereotypes, we hypothesized that people who are higher in status and authority have been observed to behave with less communion (selflessness and concern with others) and more agency (self-assertion and urge to master) than those who have lower status positions. Therefore, perceivers' observations that women occupy lower status positions than men may lead them to believe that women are more communal and less agentic than men.

By a similar logic, the differing distributions of women and men into the roles of homemaker and employee may account for the stereotypic beliefs that women are communal and men are agentic. Because the labor-force participation rates of women $(51.2 \%)$ and men (77.2\%) still differ considerably (U.S. Department of Labor, 1980), perceivers are likely to have observed fewer women than men in employee roles and almost exclusively women in the homemaker role. The perception of women as less agentic and more communal than men would follow if employees have been observed to behave more assertively and masterfully than homemakers as well as less selflessly and supportively toward others. According to this analysis, the stereotypic differences between women and men should parallel the differences that people perceive between homemakers and employees. Some empirical support for this hypothesis is provided by Clifton, McGrath, and Wick's (1976) finding that the communal attributes ordinarily ascribed to women were assigned only to housewives and not to four other categories of women (female athlete, career woman, club woman, and "bunny").

The experiments that we have carried out to test these ideas share several features of design. To minimize demand characteristics stemming from subjects' knowledge of our hypotheses, each subject read a description of only one woman or man. In addition, the aspect of social roles presumed to account for gender stereotypes (hierarchical status, or oc- 
cupation as a homemaker or employee) was varied: (a) In Experiments 1 and 2, which examined hierarchical status, some stimulus persons had high-status job titles and some had low-status job titles, and (b) in Experiment 3 , which examined the homemaker-employee distinction, some stimulus persons were homemakers and others were employees. For other stimulus persons, this stereotype-relevant aspect of the social role was omitted: (a) In the status experiments, the job title was omitted, and (b) in the homemaker-employee experiment, designation as a homemaker or employed person was omitted. It was in these experimental conditions, in which the role descriptions were omitted, that subjects should have manifested gender stereotyping. According to our analysis, perceivers view men and women stereotypically in the absence of role information, because under such conditions the attributes ascribed to women and men reflect the differing social roles that underlie the stereotypes. In contrast, the addition of role descriptions to female and male stimulus persons prevents gender-stereotypic judgments if such descriptions (e.g., job titles) provide clearcut information about the aspect of social roles that ordinarily covaries with sex (e.g., hierarchical status). In the presence of such role information, the covariation of sex and role that is the implicit basis of gender stereotypes is removed, and role would determine perceivers' beliefs about people's attributes. Women and men who have the same role would be perceived equivalently.

\section{Experiments 1 and 2}

\section{Method}

\section{Subjects}

In Experiment 1, 276 females and 208 males participated. Of these subjects, 256 were University of Massachusetts psychology students who participated in a laboratory setting to obtain extra-credit course points. An experimenter randomly selected the remaining 228 subjects by choosing on repeated occasions every fourth person seated in a University of Massachusetts coffee shop. In Experiment 2, 237 females and 243 males participated. One female and one male experimenter each randomly selected half of the subjects by choosing every fourth person seated in a coffee shop or general library at Purdue University. Especially in Experiment 1, the subjects sampled from the public campus locations included university staff as well as students. In the experiments reported in this article, $80 \%$ or more of the persons selected from such locations agreed to participate. Subjects' mean age was 22.30 years in Experiment $I$ and 21.81 years in Experiment 2.

\section{Procedure}

Each subject read a brief description of an employee (e.g., "Phil Moore is about 35 years old and has been employed for a number of years by a supermarket. He is one of the managers") and rated this stimulus person. The descriptions in Experiment 1 varied according to a $2 \times 3 \times 2$ (female vs. male $\times$ high-status job title vs. lowstatus job title vs. no job title $\times$ bank vs. supermarket setting) factorial design. The design of Experiment 2 differed with respect to the setting variable, which had four levels because a medical clinic and a university department of biology were added.

In the laboratory sessions of Experiment 1, a female experimenter administered materials to subjects in groups of about 25. Subjects first indicated their age and sex. To ensure that subjects thought carefully about the stimulus person, the experimenter had them "spend a moment thinking about" the stimulus person (after reading the description) and then write a few sentences about the person. Subjects then responded to the measures described below.

At the public campus locations in both experiments, an experimenter approached each subject by asking her or him to participate in a study on "impressions of other people." After the subject had completed the questionnaire, the experimenter asked her or his age and recorded this information along with the subject's sex.

\section{Manipulation of Independent Variables}

Sex of stimulus person. The stimulus persons were either female or male. Sex was identified by sex-typed names (e.g., Sue Fisher, Phil Moore).

Status of job title and setting of job. The stimulus persons had either a high-status job title, a low-status job title, or no job title. To provide an internal replication of the design, the stimulus persons were described as employed by a bank or a supermarket and, in Experiment 2, also by a medical clinic or a university department of biology. The high- and low-status job titles for these settings were vice-president and teller, manager and cashier, physician and $x$-ray technician, and professor and lab technician, respectively.

\section{Measuring Instruments ${ }^{1}$}

Beliefs about stereotypic attributes. Using 5-point scales, subjects rated the stimulus persons on 18 attributes, presented either as personality characteristics (Experiment 1) or as.attributes of on-the-job behavior (Experiment 2). Each on-the-job rating scale was preceded by a question asking how much of the attribute the stimulus person exhibited on the job (e.g." "How competitive do you think this person is on the job?").

\footnotetext{
${ }^{1}$ For all experiments, measures are listed in the order in which they were administered.
} 
Attributes were selected primarily from the Personal Attributes Questionnaire (Spence \& Helmreich, 1978) to ensure that they (a) represented gender stereotypes and (b) included both communal and agentic qualities. A factor analysis (varimax orthogonal rotation) of subjects' ratings was performed for each of the five experiments in this series. All analyses yielded similar two-factor solutions. One factor, labeled communal, accounted for an average of $17.4 \%$ of the variance in the five experiments, and another factor, labeled agentic, accounted for an average of $23.9 \%$ of the variance. Although various other labels have been used by researchers to characterize these dimensions (e.g., expressiveness vs. instrumentality, social orientation vs. task orientation, and femininity vs. masculinity), none provided as close a match to the actual content of the factors as did Bakan's (1966) terms, communion and agency.

The measure of perceived communion was the mean of each subject's ratings on the attributes that (in the five experiments) consistently loaded highly on the communal factor: kind, helpful, understanding, warm, aware of others' feelings, and (in all but Experiment 1, which omitted this attribute) able to devote self to others. The measure of perceived agency was the mean of each subject's ratings on the attributes that consistently loaded highly on the agentic factor: active, not easily influenced, aggressive, independent, dominant, self-confident, competitive, makes decisions easily, never gives up easily, and (in all but Experiment 1 , which omitted this scale) stands up well under pressure. These measures had satisfactory internal consistency: The mean values of coefficient alpha (Cronbach, 1951 ) in the five experiments were .84 for communion and .86 for agency. The findings of all five experiments are presented in terms of these measures. Because few significant effects were obtained on several rating scales not included in these measures, these findings will not be reported.

Inferred job status. In the laboratory portion of Experiment 1 and in Experiment 2, subjects estimated (in dollars) the stimulus person's annual salary. In Experiment 2 , for stimulus persons who had no job title, subjects also gave their "best guess" concerning the individual's job title. Coders blind to the experimental conditions divided the job titles into (a) a high-status category consisting of jobs that either included an administrative or managerial component or required high-level technical skills and (b) a low-status category of other jobs. Coders agreed on approximately $95 \%$ of these relatively objective judgments, and disagreements were resolved by discussion. In the laboratory portion of Experiment 1 , subjects also rated the status of the stimulus person's job on a 15-point scale ranging from low status to high status. ${ }^{2}$

\section{Results}

The principal data analyses were Sex of Stimulus Person $\times$ Status of Job Title $\times$ Setting analyses of variance (ANOVAs). Because no significant effects occurred in Experiment 1 for locale in which stimulus materials were administered (coffee shop vs. laboratory), this variable was dropped from the analyses re- ported here. Also, analyses including subject sex as an additional variable yielded very few differences between female and male subjects for any of the experiments in this series. ${ }^{3}$ Therefore, this variable was also dropped from all analyses reported in this article. Finally, because analyses including experimenter (female vs. male) as an additional factor yielded very few effects in Experiment 2 (or in Experiments 3 and 5, which also used one experimenter of each sex), this variable was dropped from all reported analyses.

\section{Inferred Job Status}

Salary estimates. On subjects' estimates of the stimulus persons' salaries, the main effects of sex of stimulus person and status of job title were highly significant for both Experiments 1 and $2 .^{4}$ Women were judged to have lower salaries than men: For Experiment 1, $M s=\$ 12,154$ versus $\$ 15,425$, respectively, $F(1,244)=27.24, p<.001$, and for Experiment $2, M$ s $=\$ 19,749$ versus $\$ 23,535$, respectively, $F(1,449)=15.29, p<.001$. Consistent with the significant main effects of status-for Experiment 1, $F(2,244)=50.58$, and for Experiment 2, $F(2,449)=137.28$, ps $<.001$-persons with high-status job titles were judged to earn considerably more than persons whose job titles were not given, who

\footnotetext{
${ }^{2}$ Because this rating-scale measure proved insensitive to differences between conditions, it was not included in additional studies and will not be discussed further.

${ }^{3}$ The absence of Sex of Subject $\times$ Sex of Stimulus Person interactions is noteworthy in view of research suggesting that in-group members perceive in-groups more favorably and less stereotypically and homogeneously than they perceive out-groups (e.g., Brewer, 1979; Tajfel, 1981; see also Park \& Rothbart, 1982, regarding perceptions of women and men). Perhaps this in-group-out-group bias is a manifestation of the self-enhancing tendency in person perception (e.g., Zuckerman, 1979) and occurs when respondents rate in-group members as they would rate themselves. It is likely that in the present experiments, subjects merely retrieved their concepts of various groups of people (e.g., male bank tellers, employed women, average men) and did not treat themselves as exemplars of the same-sex categories.

${ }^{4}$ Because the variance of subjects' salary estimates was extremely heterogeneous, with larger means associated with larger variances, analyses were performed on the logarithm of the salaries in all experiments in this series. There was no serious heterogeneity on the other dependent variables in these experiments.
} 
in turn were judged to earn more than persons with low-status job titles: For Experiment 1, $M s=\$ 19,236$ versus $\$ 11,773, p<.001$, and $\$ 11,773$ versus $\$ 10,120, p<, 025$; for Experiment $2, M s=\$ 32,057$ versus $\$ 18,548, p<$ .001 , and $\$ 18,548$ versus $\$ 14,359, p<.001$. The Sex $\times$ Status interactions were nonsignificant, $F(2,244)=1.64$ and $F(2,449)=1.61$.

The findings that women were judged to have lower salaries than men, regardless of whether job titles were indicated, suggest that the salary estimates may have functioned largely as a measure of perceived wage discrimination. To provide clear-cut evidence that lower status was associated with women more than with men, the tendency to ascribe lower salaries to women should have been especially strong in conditions omitting job titles, in which the typical status difference was not countered by information that equated women's and men's jobs. Thus the absence of the expected Sex $\times$ Status interaction in Experiment 1 led us to include a purer indicator of status, job title guesses, in Experiment 2.

$J o b$ title guesses. For stimulus persons without job titles in Experiment 2, a greater proportion of subjects' job-title guesses were categorized as high status (vs. low status) for male than for female stimulus persons. Highstatus job titles were ascribed to $\mathbf{4 8}$ men and 30 women, and low-status job titles were ascribed to 30 men and 39 women. A loglinear analysis of the cell frequencies (Bishop, Fienberg, \& Holland, 1975; Davis, 1974) revealed a significant likelihood ratio chi-square $\left(G^{2}=\right.$ $4.82, p<.05$ ) for the interaction between sex of stimulus person and judged job-title status. Thus the job-title measure of inferred status yielded clear evidence that without knowing job titles, subjects inferred that women held lower status positions than men.

\section{Beliefs About Stereotypic Attributes}

Subjects' mean ratings of the stimulus persons' communion and agency appear in Tables 1 and 2. On communion, the main effect of sex of stimulus person was marginally significant in Experiment 1 and significant in Experiment 2 . Women were perceived as more communal than men: For Experiment $1, M \mathrm{~s}=$ 3.61 versus 3.48 , respectively, $F(1,472)=3.71$, $p<.06$; for Experiment $2, M \mathrm{~s}=3.53$ versus
Table 1

Mean Ratings of Stereotypic Attributes of Female and Male Employees Who Varied in Status

of Job Title: Experiment 1

\begin{tabular}{llll}
\hline $\begin{array}{l}\text { Stimulus } \\
\text { person }\end{array}$ & $\begin{array}{c}\text { High } \\
\text { status }\end{array}$ & $\begin{array}{c}\text { Low } \\
\text { status }\end{array}$ & $\begin{array}{r}\text { No } \\
\text { title }\end{array}$ \\
\hline $\begin{array}{l}\text { Female } \\
\text { Communal }\end{array}$ & 3.55 & 3.59 & 3.69 \\
$\quad$ Agentic & 3.74 & 2.63 & 2.85 \\
Male & & & \\
Communal & 3.41 & 3.58 & 3.48 \\
Agentic & 3.52 & 2.43 & 2.78 \\
\hline
\end{tabular}

Note. Means are on a 5-point scale; larger numbers indicate greater communion or agency. Cell $n s$ ranged from 78 to 85. For communal, $M S_{c}=0.54$; for agentic, $M S_{\varepsilon}=0.44$.

3.34, $F(1,456)=9.95, p<.002$. Consistent with a significant Sex $\times$ Status interaction in Experiment 2 only, $F(2,456)=3.46, p<.05$, this stronger communal tendency was ascribed to women (vs. men) with low-status or no job titles ( $p s<.01$ or smaller) but was nonsignificant with high-status job titles.

On agency, the main effects of sex and status were highly significant in both experiments. Women were perceived as more agentic than men: For Experiment $1, M \mathrm{~s}=3.08$ versus 2.92, respectively, $F(1,472)=7.80, p<.005$; for Experiment $2, M s=3.53$ versus 3.37, $F(1$, $456)=9.99, p<.002$. Consistent with the significant main effects of status-for Experiment $1, F(2,472)=121.01$, and for Experiment $2, F(2,456)=21.33$, ps $<.001$-persons with high-status job titles were perceived as

Table 2

Mean Ratings of On-the-Job Behavior of Female and Male Employees Who Varied in Status of Job Title: Experiment 2

\begin{tabular}{lccc}
\hline $\begin{array}{c}\text { Stimulus } \\
\text { person }\end{array}$ & $\begin{array}{c}\text { High } \\
\text { status }\end{array}$ & $\begin{array}{c}\text { Low } \\
\text { status }\end{array}$ & $\begin{array}{r}\text { No } \\
\text { title }\end{array}$ \\
\hline $\begin{array}{l}\text { Female } \\
\text { Communal }\end{array}$ & 3.48 & 3.53 & 3.57 \\
$\begin{array}{l}\text { Agentic } \\
\text { Male }\end{array}$ & 3.77 & 3.37 & 3.46 \\
Communal & 3.51 & 3.21 & 3.30 \\
Agentic & 3.61 & 3.23 & 3.25 \\
\hline
\end{tabular}

Note. Means are on a 5-point scale; larger numbers indicate greater communion or agency. All cell $n s=80$. For communal, $M S_{e}=0.41$; for agentic, $M S_{\varepsilon}=0.34$. 
more agentic than persons whose job titles were not given or persons with low-status job titles: For Experiment $1, M \mathrm{~s}=3.63$ versus 2.81 for high-status versus no job title and 3.63 versus 2.53 for high- versus low-status job title, respectively, $p \mathrm{~s}<.001$; for Experiment $2, M \mathrm{~s}=$ 3.69 versus 3.36 , and 3.69 versus 3.30 , respectively, $p s<.001$. In Experiment 1 , the contrast between the no job title and lowstatus job title conditions was also significant $(p<.001) .^{5}$

\section{Discussion}

Several aspects of these findings are unfavorable to the hypothesis that the stereotypes of female communion and male agency stem from having observed women in lower status roles than men. First, our status-difference explanation of gender stereotypes implies that perceptions of lower status persons resemble those of average women and that perceptions of higher status persons resemble those of average men. This expectation was only partly confirmed: Persons with low-status job titles were perceived as considerably less agentic than persons with high-status job titles, but there was no difference in communion.

The second and most surprising aspect of the findings that discount the status hypothesis is the counterstereotypic effect that the sex of the stimulus persons had on the ascription of agentic traits. Women were perceived as more agentic than men despite the perceptions that (a) women earn less than men and hold lower status positions and (b) persons in lower status positions are less agentic than persons in higher status positions. Furthermore, women were perceived as more communal than men, even though persons in lower and higher status positions did not differ in perceived communion.

These perceived sex differences were relatively small, despite their statistical significance. The differences were no larger than .19 on a 5-point scale, with an effect size $(d)$ of .30 (Cohen, 1977). Nevertheless, several aspects of the experiments promote confidence in the reliability of the findings. First, the generalizability of the findings across subjects recruited at two universities and by two different methods (subject pool and random sampling at public campus locations) reduces the likelihood that artifacts arose from particular subject populations. Second, the generalizability of the findings across four organizational settings reduces the likelihood that artifacts arose from beliefs about particular work environments. Third, the generalizability of the findings across two different types of ratings (personality traits and on-the-job behavior) reduces the likelihood that artifacts arose from insufficient sensitivity of global trait ratings. Because inferences from job titles to attributes of on-the-job behavior should be easier and more direct than inferences from job titles to personality traits, the job behavior ratings of Experiment 2 should have maximized the possibility of obtaining any effects of explicit and implicit variation of job status.

Our findings may be more consistent with the hypothesis that distributions of women and men into homemaker and employee roles underlie gender stereotypes. Because all of the stimulus persons presented in Experiments 1 and 2 were described as employed, the relative absence of gender-stereotypic perceptions may reflect the inclusion of this information about occupational role. Therefore, our third experiment tested the hypothesis that gender stereotypes stem from perceivers' observations of the distribution of women and men into the roles of homemaker and employed person. In this experiment, some female and male stimulus persons were described as employees and some as homemakers, and the occupation of others was not indicated.

One implication of the homemaker versus employee explanation of gender stereotypes is that the differences perceived between persons in these two occupational roles parallel the stereotypic differences between women and men. Therefore, homemakers were expected to be perceived as more communal and less agentic than employed persons. It also follows that women and men are perceived stereotypically when their role assignment as home-

\footnotetext{
${ }^{5}$ In Experiments 1 and 2, several effects of employment setting were also obtained on beliefs and on inferred status. Only one of these effects involved the sex of the stimulus persons. Consistent with this Sex $\times$ Setting interaction obtained in Experiment 2 on perceived agency $(p<.01)$, subjects rated women's behavior as more agentic than men's in the bank and the supermarket ( $p s<.01)$, as marginally more agentic than men's in the university department of biology $(p<.09)$, but not different from men's in the medical clinic.
} 
maker or employee is unknown, because perceivers have observed that more women than men are homemakers and fewer women are employees. Furthermore, the homemakeremployee analysis implies that women and men are perceived similarly if they have the same occupational role, that is, if both are homemakers or both are employees. Yet, consistent with the agency findings of the first two experiments and inconsistent with our social role analysis, we expected that female employees would be perceived as somewhat more agentic than male employees. We were less confident that female employees would be perceived as more communal because of the marginal significance of this finding in Experiment 1 .

The design of our third experiment also allowed us to examine two possible explanations of the relatively high agency ratings of employed women. One explanation is that repondents are no longer willing to derogate women on stereotype questionnaires because of changes in attitudes toward women, greater wariness about revealing one's stereotyping, or possibly other causes. This explanation implies that it would be impossible to replicate the stereotypes of women and men obtained by other investigators (e.g., Broverman et al., 1972; Spence \& Helmreich, 1978). The inclusion of average woman and average man cues in our third experiment allowed us to examine this issue.

According to another explanation for the high level of agency ascribed to employed women, subjects believed that women are less likely to be employed than men and therefore inferred that higher standards are applied to women than to men by employers (or by women themselves) when women are selected for jobs. This selection hypothesis implies that people who are thus highly selected (or selfselected) for a role are believed to be more extreme in role-relevant characteristics. If agentic qualities are believed to be relevant to job success, employed women would be perceived as being more agentic than employed men. It also follows that male homemakers would be perceived as being more communal than female homemakers (provided that communal characteristics are believed to be relevant to the homemaker role). The inclusion of homemaker stimulus persons (as well as employees) allowed us to examine these selection considerations.

The greater agency ascribed to employed women (vs. men) is not plausibly explained in terms of a belief that discrimination makes it necessary for female employees to be more qualified than their male counterparts. People are likely to believe that discrimination exists in relation to high-status positions or other male-dominated jobs, for which traditionally there were barriers excluding or discouraging women. However, in Experiments 1 and 2, subjects were found to believe in women's superiority in agentic qualities when low-status as well as high-status job titles were given. It seems unlikely that subjects believed that women face discrimination in obtaining the low-status positions used in our research (e.g., bank teller, supermarket cashier).

\section{Experiment 3 \\ Method}

\section{Subjects}

A total of 108 females and 132 males participated. One female and one male experimenter each randomly selected half of the subjects by choosing persons seated in a coffee shop or general library at Purdue University. The subjects' mean age was 21.61 years.

\section{Procedure}

Each subject read a brief description (e.g., "an average man" or "an average woman who is employed full-time") and rated this stimulus person. The descriptions varied according to a $2 \times 3$ (female vs. male $\times$ employee vs. homemaker vs. no occupational description) factorial design.

\section{Manipulation of Independent Variables}

Sex of stimulus person. The stimulus persons were described as an average woman or as an average man.

Occupation of stimulus person. The stimulus persons were described as employed full-time, or as caring for a home and children and not employed outside of the home, or no occupational description was provided.

\section{Measuring Instruments}

Beliefs about stereotypic attributes. The measures described for Experiment 1 were used.

Inferred likelihood of employment. For the stimulus persons for whom no occupational description was provided, subjects indicated on an 11-point scale, ranging from $0 \%$ chance to $100 \%$ chance, the likelihood that the person was employed full-time.

Inferred job status. For stimulus persons described as employed full-time, the salary measure described in Experiment 1 was used. 


\section{Results}

The principal data analyses were Sex of Stimulus Person $\times$ Occupation of Stimulus Person ANOVAs.

\section{Inferred Likelihood of Employment and Inferred Job Status}

Subjects who received no occupational information about the stimulus person inferred that the woman was less likely than the man to be employed full-time ( $M \mathrm{~s}=56.50 \% \mathrm{vs}$. $79.75 \%$, respectively), $F(1,78)=30.39, p<$ .001 . Subjects who rated employees ascribed lower salaries to the woman $(M=\$ 15,615)$ than the man $(M=\$ 21,193), F(1,78)=13.06$, $p<.001$.

\section{Beliefs About Stereotypic Attributes}

Subjects' mean ratings of communion and agency appear in Table 3. On communion, the significant main effects of sex, $F(1,234)=$ $13.32, p<.001$, and occupation, $F(2,234)=$ $49.08, p<.001$, should be interpreted in the context of a significant Sex $\times$ Occupation interaction, $F(2,234)=12.34, p<.001$. These effects are best described in terms of the planned contrasts implied by the hypotheses. As expected, homemakers, regardless of their sex, were perceived as more communal than employees $(p<.001$ for female stimulus persons; $p<.005$ for male stimulus persons). In addition, for stimulus persons without occupational descriptions, the traditional gender stereotype of the woman as being more communal than the man was obtained $(p<.001)$. The female and male employees were not perceived to differ in communion, nor were the female and male homemakers. The communal tendency of the woman whose occupation was not given was less than that of the female homemaker $(p<.001)$ but greater than that of the employed woman $(p<.001)$. The communal tendency of the man whose occupation was not given was less than that of the male homemaker $(p<.001)$ or of the employed $\operatorname{man}(p<.005)$.

On agency, the significant main effect of occupation, $F(2,234)=21.88, p<.001$, should be interpreted in the context of the significant Sex $\times$ Occupation interaction, $F(2$, $234)=10.14, p<.001$. According to the
Table 3

Mean Ratings of Stereotypic Attributes of

Females and Males Who Varied in

Occupation: Experiment 3

\begin{tabular}{lccc}
\hline $\begin{array}{c}\text { Stimulus } \\
\text { person }\end{array}$ & Employee & Homemaker & $\begin{array}{c}\text { No } \\
\text { occupational } \\
\text { description }\end{array}$ \\
\hline Female & & & \\
$\quad \begin{array}{l}\text { Communal } \\
\text { Agentic }\end{array}$ & 3.31 & 4.22 & 3.81 \\
$\begin{array}{l}\text { Male } \\
\text { Communal }\end{array}$ & 3.69 & 3.02 & 3.00 \\
Agentic & 3.39 & 4.11 & 3.03 \\
\hline
\end{tabular}

Note. Means are on a 5-point scale; larger numbers indicate greater communion or agency. All cell $n s=40$. For communal, $M S_{\mathrm{e}}=0.33$; for agentic, $M S_{\mathrm{e}}=0.31$.

planned contrasts, employees (regardless of their sex) were perceived as more agentic than homemakers ( $p s<.001$ for female and male stimulus persons). In addition, for stimulus persons without an occupational description, the traditional gender stereotype of the man as more agentic than the woman was obtained $(p<.001)$. The female employee was perceived as more agentic than the male employee $(p<$ .025 ), whereas the female and the male homemaker were not perceived to differ. The agentic tendency of the woman without an occupational description did not differ from that of the female homemaker but was less than that of the female employee $(p<.001)$. The agentic tendency of the man without an occupational description was greater than that of the male homemaker $(p<.001)$ but not different from that of the male employee.

These ANOVA findings are generally consistent with the theory that gender stereotypes stem from the observed distribution of women and men into homemaker and employee roles. Therefore, it is worthwhile to examine the correlations between (a) inferred role distributions of the stimulus persons who lacked occupational descriptions and (b) the ascription of gender-stereotypic attributes to them. Overall, the higher the inferred likelihood that the average woman or man was employed, the lower was her or his communion, $r(78)=-.34$, $p<.01$, and the higher was her or his agency, $r(78)=.41, p<.001$. Yet inferred likelihood of employment should have been a stronger predictor of stereotypic perceptions for the 
woman than for the man. This differential predictability would be expected because likelihood of employment for the average man was relatively invariant $(S D=15.61$ for average man vs. 21.31 for average woman), $F(39$, $39)=1.86, p<.05$, no doubt because this likelihood was generally quite high (see the previous subsection of results). For the woman, greater inferred likelihood of employment was associated with slightly less communion, $r(38)=-.19, p<.25$, and greater agency, $r(38)=.43, p<.01$. For the man, the correlations between inferred likelihood of employment and perceived communion, $r(38)=$ .13 , and agency, $r(38)=.01$, were very small and nonsignificant.

\section{Discussion}

The findings of Experiment 3 were generally favorable to the hypothesis that a sex difference in the distribution of women and men into homemaker and employee roles underlies the stereotype that women are communal and men are agentic. Two findings confirmed prerequisite conditions for testing this hypothesis: (a) The average woman and man without occupational descriptions were perceived stereotypically (i.e., the woman was perceived as more communal and the man as more agentic), and (b) the average man was judged as considerably more likely than the average woman to be employed.

The correlational analyses relating likelihood of employment to the attributes of the average woman and man provided one test of whether observations of women's and men's differing occupational roles account for stereotypes. The likelihood that the average woman was employed related positively to her agency and negatively (albeit weakly) to her communion. In other words, subjects who reported that women are often employed tended to view women counterstereotypically, and those who reported that women are less often employed (and presumably more often homemakers) tended to view women stereotypically. Comparable findings were not obtained for men, probably because they are generally employees and rarely homemakers in the naturally occurring situations in which subjects had made their previous observations.

The ANOVA findings concerning the attri- butes of the stimulus persons whose occupations were described reveal even more clearly that social roles underlie gender stereotypes. Subjects believed that, regardless of sex, persons described as homemakers differed from persons described as employees. Female and male homemakers were perceived to be like stereotypic women (high in communion and low in agency), whereas female and male employees were perceived to be like stereotypic men (low in communion and high in agency). Another important aspect of subjects' beliefs about the stimulus persons with occupational descriptions is that the females and males were perceived relatively equivalently once their social role as employee or homemaker was specified. The only exception to this pattern, and an exception that demands explanation, is the significantly greater perceived agency of employed women compared with employed men.

The comparisons between same-sex persons who differed in occupation were also moderately consistent with our role-distribution theory of gender stereotypes. Because subjects judged that there was roughly a 50-50 chance that the average woman was employed, perceptions of her personal attributes should have fallen between those of the employed woman and the female homemaker. Although this expectation was fulfilled (see Table 3 ), the average woman's perceived agency did not differ significantly from that of the homemaker. Because subjects considered it quite likely that the average man was employed, their beliefs about his personal attributes should have been similar to their beliefs about the employed man. This expectation was fulfilled for agency, but the average man was perceived as significantly less communal than the employed man. ${ }^{6}$

\footnotetext{
${ }^{6}$ In the interpretation of these findings, subjects' judgments of the probability that the average woman and man are employed should not be treated as exact estimates of the observed distributions of people into employee and homemaker roles. One reason for our caution is that males who are not employed have probably been observed in largely different roles than females who are not employed. Whereas such females are usually homemakers, probably such males are retired or seeking employment. Therefore, the subjects' judgment that there is an $80 \%$ chance that the average man is employed does not imply that $20 \%$ of men have been observed as homemakers. It also does not
} 
Although the findings of this experiment are generally supportive of the idea that perceived sex differences stem from perceivers' observations of women and men in differing occupational roles, they do not explain the tendency for employed women to be perceived as more agentic than employed men. ${ }^{7}$ It is noteworthy that this finding was obtained in Experiments 1 and 2 for the stimulus persons without job titles as well as in Experiment 3 for the average employed persons because these stimulus persons were probably thought to have lower status positions if they were female. As demonstrated in Experiments 1 and 2, lower status employees were believed to be less agentic than higher status employees; therefore, any tendency to ascribe lower status to women would tend to counteract any factors making them appear more agentic than men.

Both of the explanations that we introduced earlier for this sex difference in agentic qualities were discounted by the findings from Experiment 3 . The idea that subjects would be unwilling to derogate women on stereotype questionnaires was discounted by their perception of the average woman as significantly less agentic than the average man. The other explanation of female employees' greater agency was that categories of people (e.g., women) who are relatively uncommon in a social role (e.g., employee) are believed to be more stringently selected in terms of the requirements of the role than people who commonly occupy the role. This explanation was discounted by the finding that the male homemaker, who is considerably rarer than the female employee, was not perceived to differ from the female homemaker in communion, the quality that subjects believed typical of homemakers. ${ }^{8}$

Yet another explanation of employed women's higher agency is that this perceived gender difference reflects a semantic or response-language difference in the way males and females are judged (e.g., Manis, 1971; Upshaw, 1969)

imply that the average man's personality attributes would be perceived as between those ascribed to employees and those ascribed to homemakers. Perhaps the low level of communion ascribed to the average man reflects the unfavorably evaluated roles ascribed to the $20 \%$ of men not thought to be employed (e.g., being retired, seeking employment). rather than a difference in how they are perceived. If stimulus persons are implicitly compared with same-sex reference groups, this semantic interpretation suggests that female employees are implicitly compared with other females and therefore are judged as very agentic, whereas male employees are implicitly compared with other males and therefore are judged as not especially agentic. This interpretation also suggests that male homemakers are implicitly compared with other males and therefore are judged as very communal, whereas female homemakers are implicitly compared with other females and therefore are not judged as especially communal. Although female employees were perceived as more agentic than male employees, male homemakers were not perceived as more communal than female homemakers. The fact that female and male homemakers were perceived equivalently, then, does not support the explanation that the perceived sex differences are an artifact of differences in the reference group implicitly used by subjects when rating females and males. Yet so little is known about how people use implicit comparison standards that we cannot be completely certain that such a process has no relevance to our findings.

Because our experiments so consistently revealed that female employees were perceived as more agentic than their male counterparts and because this finding is counterstereotypic and perhaps important, we considered another explanation of the finding. Accordingly, the fact that employed women often balance

\footnotetext{
${ }^{7}$ Other investigators have reported higher perceived agency and competence in females than males, yet in these studies the situation faced by the stimulus person was judged to be especially difficult or demanding for women (Abramson, Goldberg, Greenberg, \& Abramson, 1977; Taynor \& Deaux, 1973), or the stimulus materials may have implied employment or special competence (Deaux \& Lewis, in press). Also, in Experiment 3 the communal ratings of employed women and men did not differ (although they did differ significantly in Experiment 2 and marginally in Experiment 1). Therefore, only the sex difference in employees' agency appears reliable and consequently requires explanation.

${ }^{8}$ Yet it could be that this selection hypothesis pertains to the employee role (because perceivers know that people are screened for employment) but not to the homemaker role (because perceivers are uncertain about whether people are screened for the occupation of homemaker).
} 
two demanding roles-homemaker and employee-may account for the relatively high agency ratings of such women. Perceivers may have observed these agentic qualities among the women who experience this potential role overload and role conflict.

To enable us to test this "double-burden" explanation, subjects in a fourth experiment rated the personality attributes of an employed woman or man described as either married or single and as either having or not having children at home. Other subjects rated an employed woman or man whose marital and parental statuses were not described. Should the double-burden explanation of women's greater agency be correct, employed women with family responsibilities, especially involving children, would be regarded as particularly agentic. Family responsibilities would increase the agency ascribed to employed men only if such men did not have wives who typically would carry out the household duties. The single father would fulfill this criterion and, as a consequence, might also be perceived as especially agentic.

\section{Experiment 4 Method}

\section{Subjects}

A total of 108 females and 135 males participated in groups of about 15 in a laboratory setting to fulfill a psychology course requirement at Purdue University. One female experimenter administered all stimulus materials. Subjects' mean age was 19.33 years.

\section{Procedure}

Each subject read a brief description of a full-time employee (e.g., "an average man who is employed full-time, is married, and has no children") and rated this stimulus person. The descriptions varied according to a $2 \times 2 \times$ 2 (employed female vs. employed male $\times$ married vs. not married $X$ children at home vs. no children at home) factorial design. Two control conditions were provided: a female for whom neither marital nor parental status was provided and a male for whom neither status was provided.

\section{Manipulation of Independent Variables}

Sex of stimulus person. The stimulus persons were described as an average employed woman or an average employed man.

Marital status of stimulus person. The stimulus persons whose marital status was provided were described as married or as not married. For the remaining stimulus persons, no information about marital status was provided.
Parental status of stimulus person. The stimulus persons whose parental status was provided were described as having children at home or not having children. (The unmarried woman or man with children at home was further described as a "single parent," to aid subjects in interpreting this potentially ambiguous description.) For the remaining stimulus persons, no information about children was provided.

\section{Measuring Instruments}

Subjects' beliefs about stereotypic attributes and job status were assessed using measures described in Experiment 1 . The subjects also estimated the number of hours that the stimulus person worked per day doing household and family-related work. For stimulus persons whose marital and parental statuses were not provided, subjects used an 11-point rating scale, ranging from $0 \%$ to $100 \%$ chance, to rate the likelihood that the person was married. On a second, similar scale, the subjects rated the likelihood that the person had children at home.

\section{Results and Discussion}

The principal data analyses were Sex of Stimulus Person $\times$ Marital Status of Stimulus Person $\times$ Parental Status of Stimulus Person ANOVAs, with the error term including the two control conditions, which omitted the information about marital and parental statuses.

\section{Inferences About Marriage, Children, Household Work, and Job Status}

For employees whose marital and parental statuses were omitted, the woman was judged less-likely to be married $(M=54.17 \%)$ than the $\operatorname{man}(M=76.00 \%), F(1,47)=20.50, p<$ .001 . She was also judged less likely to have children at home than her male counterpart $(M \mathrm{~s}=43.75 \%$ versus $66.00 \%$, respectively), $F(1,47)=16.22, p<.001$. Thus subjects did not consider it highly likely that the average employed woman faced a double burden of family and employment responsibilities.

Analyses of subjects' estimates of the number of hours per day the employed persons spent doing household and family-related work revealed only one significant effect: Persons with children were judged to do more work than persons without children $(M \mathrm{~s}=4.91$ versus 3.34, respectively), $F(1,233)=6.96, p<$ .01 . Subjects failed to acknowledge that married female employees spend more time on household work than married male employees, even though this sex difference has been well documented in sociological literature on housework (e.g., Hartmann, 1981). 
Analyses of subjects' salary estimates replicated the effect of sex obtained in our previous experiments: Women were judged to have lower salaries than men $(M \mathbf{s}=\$ 18,074$ versus $\$ 25,055$, respectively), $F(1,233)=$ $38.29, p<.001$.

\section{Beliefs About Stereotypic Attributes}

Subjects' mean ratings of communion and agency appear in Table 4 . On communion, the main effects of marital and parental statuses were both significant. Married employees were judged as being more communal than single employees $(M \mathrm{~s}=3.54$ versus 3.26 , respectively), $F(1,233)=9.60, p<.01$. Employees with children at home were judged as more communal than employees without children at home $(M \mathrm{~s}=3.68$ versus 3.11 , respectively), $F(1,233)=41.75, p<.001 .^{9}$

On agency, only the sex effect proved significant: Replicating the three previous experiments, female employees were perceived as more agentic than male employees $(M \mathrm{~s}=$ 3.75 versus 3.59 , respectively), $F(1,233)=$ $7.27, p<.01$, calculated on the basis of all 10 conditions. ${ }^{10}$ Thus, contrary to the doubleburden hypothesis, neither marital nor parental status influenced the agency ascribed to employed women or men.

In view of this nonconfirmation of the double-burden explanation of women's perceived agency and in view of the continued reliability of the finding itself, we considered yet another explanation: Perhaps employed women are considered more agentic than their male counterparts because they are more likely to have chosen to be employed. Because agency evidently typifies employees (perhaps because most jobs require and reward agentic behavior), observing that women often are employed by choice may have led perceivers to infer that such women are agentic. This explanation of the effects of choice on stereotype formation follows from correspondent inference theory (Jones \& Davis, 1965), which suggests that perceivers more often infer that an employee possesses the personal qualities she or he manifests behaviorally if it appears that the employee has freely chosen to work and has not been required to work by virtue of her or his life situation or sex role.

In a test of this freedom-of-choice expla- nation, subjects in a fifth experiment rated the personal attributes of a female or male employee described as employed by choice or employed out of necessity. Other subjects rated a female or male employee about whom no choice information was provided.

\section{Experiment 5 \\ Method}

\section{Subjects}

A total of 110 females and 132 males participated. One female and one male experimenter each randomly selected half of the subjects by choosing persons seated in a coffee shop or general library at Purdue University. Subjects' mean age was 20.59 years.

\section{Procedure}

Each subject read a brief description of a full-time employee [e.g., "an average woman who is employed fulltime and who is employed because she wants to work (and not because she has to work)"] and rated this stimulus person. The descriptions varied according to $2 \times 3$ (female vs. male $X$ employed by choice vs. employed out of necessity vs. no choice information) factorial design.

\section{Manipulation of Independent Variables}

Sex of stimulus person. The stimulus persons were described as an average employed woman or an average employed man.

Choice of stimulus person to be employed. The stimulus persons were described as employed because they want to work and not because they have to work or employed because they have to work and not because they want to work, or no information about employment choice was provided.

\section{Measuring Instruments}

Subjects' beliefs about stereotypic attributes and job status were assessed with the measures described in Ex-

\footnotetext{
${ }^{9}$ Consistent with a Sex of Stimulus Person $\times$ Parental Status of Stimulus Person interaction, $F(1,233)=5.86$, $p<, 05$, male employees with children at home were perceived as considerably more communal than male employees without children at home $(M \mathrm{~s}=3.76$ versus 2.97 , respectively, $p<.001$ ), whereas female employees with children at home were not perceived as so greatly different $(M=3.59)$ from female employees without children at home $(M=3.25$ ), although this difference remained significant for the females $(p<.01)$.

${ }^{10}$ For all five role descriptions, the female agency mean was larger than the male mean. Yet this agency sex difference became quite small for the stimulus persons for whom marital and parental statuses were not described. However, in this female stimulus-person condition, there were two unusually low agency scores.
} 
Table 4

Mean Ratings of Stereotypic Attributes of Female and Male Employees Who Varied in Marital and Parental Statuses: Experiment 4

\begin{tabular}{llcccc}
\hline $\begin{array}{c}\text { Stimulus } \\
\text { person }\end{array}$ & $\begin{array}{c}\text { Married/ } \\
\text { children }\end{array}$ & $\begin{array}{c}\text { Married/no } \\
\text { children }\end{array}$ & $\begin{array}{c}\text { Single/ } \\
\text { children }\end{array}$ & $\begin{array}{c}\text { Single/no } \\
\text { children }\end{array}$ & $\begin{array}{c}\text { No } \\
\text { description }\end{array}$ \\
\hline $\begin{array}{l}\text { Female } \\
\text { Communal }\end{array}$ & 3.77 & & & & \\
Agentic & 3.70 & 3.38 & 3.42 & 3.11 & 3.30 \\
Male & & 3.83 & 3.91 & 3.84 & 3.49 \\
Communal & 3.86 & 3.10 & 3.66 & 2.87 & 3.40 \\
Agentic & 3.59 & 3.54 & 3.75 & 3.60 & 3.45 \\
\hline
\end{tabular}

Note. Means are on a 5-point scale; larger numbers indicate greater communion or agency. Cell ns ranged from 22 to 27. For communal, $M S_{\varepsilon}=0.37$; for agentic, $M S_{\mathrm{e}}=0.24$.

periment 1. For the stimulus persons about whom no choice information was provided, subjects used an 11-point scale, ranging from $0 \%$ to $100 \%$ chance, to rate the likelihood that the person worked "because she [he] has to and not because she [he] wants to."

\section{Results}

The principal data analyses were Sex of Stimulus Person $\times$ Choice of Stimulus Person to Be Employed ANOVAS.

\section{Inferred Likelihood of Employment Out of Necessity and Inferred Job Status}

The average employed woman was judged less likely to be employed out of necessity than the average employed man $(M \mathrm{~s}=48.75 \%$ versus $67.33 \%$, respectively), $F(1,78)=11.50$, $p<.01$. Also, women were judged to have lower salaries than men $(M \mathrm{~s}=\$ 16,330$ versus $\$ 23,983$, respectively), $F(1,235)=55.81, p<$ .001 . The main effect of the stimulus person's choice to be employed, $F(2,235)=17.78, p<$ .001 , revealed that higher salaries were ascribed to employees working by choice ( $M=$ $\$ 23,265$ ) or to employees without choice information $(M=\$ 21,304)$ than to employees working out of necessity $(M=\$ 15,977$, ps $<.001)$.

\section{Beliefs About Stereotypic Attributes}

Subjects' mean ratings of communion and agency appear in Table 5 . On communion, only the main effect of choice proved significant, $F(2,236)=7.41, p<.001$ : Greater communion was ascribed to employees working by choice $(M=3.43)$ or employees without choice information $(M=3.35)$ than to em- ployees working out of necessity $(M=3.10$, $p s<.01$ or smaller).

On agency, the main effects of sex and choice were both significant, as was the interaction between these variables. Women were perceived as more agentic than men $(M s=3.54$ vs. 3.30 , respectively), $F(1,236)=12.34, p<$ .001 . Consistent with the choice main effect, $F(2,236)=89.54, p<.001$, employees working by choice were perceived as more agentic than employees without choice information ( $M \mathrm{~s}=3.86$ versus $3.59, p<.002$, respectively), who in turn were more agentic than employees working out of necessity $(M=2.80, p<.001)$. Consistent with the Sex $\times$ Choice interaction, $F(2,236)=3.46, p<.05$, the tendency for women to be perceived as more agentic than men was significant for employees without choice information $(p<.001)$ and employees working out of necessity $(p<.025)$ and nonsignificant for employees working by choice. Note also that for women, the agency of the employee working by choice did not differ from that of the employee without choice information, and these two employees were more agentic than the employee working out of necessity ( $p s<.001)$. For men, the agency of the employee working by choice was greater than that of the employee with no choice information $(p<.001)$, and these two employees were more agentic than the employee working out of necessity ( $p s<.001$ ).

These ANOVA findings generally support the hypothesis that employed women are perceived as more agentic than employed men, because women have been observed to exercise greater choice about being employed. Thus it is worthwhile to examine, for employees about 
Table 5

Mean Ratings of Stereotypic Attributes of Female and Male Employees Who Varied in Choice to Be Employed: Experiment 5

\begin{tabular}{lccc}
\hline $\begin{array}{c}\text { Stimulus } \\
\text { person }\end{array}$ & $\begin{array}{c}\text { Employed } \\
\text { by choice }\end{array}$ & $\begin{array}{c}\text { Employed } \\
\text { out of } \\
\text { necessity }\end{array}$ & $\begin{array}{c}\text { No choice } \\
\text { information }\end{array}$ \\
\hline $\begin{array}{c}\text { Female } \\
\text { Communal }\end{array}$ & 3.38 & 3.23 & 3.41 \\
$\begin{array}{c}\text { Agentic } \\
\text { Male }\end{array}$ & 3.86 & 2.95 & 3.80 \\
Communal & 3.45 & 2.98 & 3.27 \\
Agentic & 3.85 & 2.66 & 3.38 \\
\hline
\end{tabular}

Note. Means are on a 5-point scale; larger numbers indicate greater communion or agency. Cell $n s$ ranged from 40 to 41. For communal, $M S_{\mathrm{e}}=0.31$; for agentic, $M S_{\mathrm{e}}=0.27$.

whom no choice information was provided, the correlation between freedom of choice and agency. Overall, the more likely an employee was to be regarded as working out of necessity rather than choice, the lower was her or his agency, $r(78)=-.40, p<.001$. However, this relation was considerably stronger for the female employee, $r(38)=-.55, p<.001$, than the male employee, $r(38)=-.09, n s$.

\section{Discussion}

In Experiment 5, the average employed woman was once again rated as more agentic than the average employed man, and the findings of this experiment favored the hypothesis that this sex difference stems from perceivers' observations that women are more likely than men to have chosen to be employed. One of the findings favoring this hypothesis is that the average employed woman was judged as more likely than the average employed man to be working by choice rather than necessity. Furthermore, on a correlational basis, the less likely subjects believed it was that the average employed woman works out of necessity, the more agency they ascribed to her.

Stronger evidence that sex differences in choice to be employed underlie the greater perceived instrumentality of female (vs. male) employees is provided by subjects' beliefs about the agency of employees described as either having or lacking freedom of choice. The choice information strongly affected agency ratings in the expected direction: $\mathrm{Re}-$ gardless of their sex, employees working by choice were perceived as more agentic than employees working out of necessity. Furthermore, perceived agency was similar for the women and men about whom choice information was provided. When employed by choice, the woman and the man did not differ in agency, although when employed out of necessity, the woman was perceived as somewhat more agentic than the man. ${ }^{11}$

In addition, it should be noted that the comparisons between stimulus persons of the same sex are relatively consistent with our freedom-of-choice hypothesis. Because subjects believed that it was moderately likely that the average employed woman had freedom of choice, her agency should have been perceived as similar to that of the woman employed by choice. As expected, the agency of the average employed woman did not differ from that of the woman employed by choice, and it was greater than that of the woman employed out of necessity. Because subjects believed that it was moderately unlikely that the average employed man had freedom of choice, his agency should have been perceived as lower than that of the man employed by choice. As expected, the agency of the average employed man was lower than that of the man employed by choice although higher than that of the man employed out of necessity.

Even though the communion findings are not relevant to our hypothesis, it should be noted that lack of choice also lowered the stimulus persons' communal tendency. The fact that the effect of choice on communion was weaker than its effect on agency may explain why women's greater freedom of choice did not cause female employees to be perceived as more communal than male employees, as well as more agentic. Consistent with the weak

\footnotetext{
1 The meaning of these comparisons is necessarily somewhat ambiguous because the choice information may have had different implications for males than for females. For example, a man employed by choice may be perceived as independently wealthy, whereas a woman employed by choice may be perceived as married and merely in comfortable financial circumstances. Similarly, a woman employed out of necessity may be perceived as single or in especially poor financial circumstances, whereas a man employed out of necessity may be perceived as fairly typical of all men (as suggested by the findings presented above).
} 
effect of choice on communion, in this series of experiments, nonsignificant tendencies in the female direction were found in the majority of communion comparisons, and in Experiment 2 , which had a large number of subjects, the comparison reached significance.

As we noted earlier, the relation between freedom of choice and agency may be attributionally mediated. Because jobs are thought to require agentic behavior, observations that members of a particular group are generally employed by choice may favor the correspondent inference that such people possess agentic personality attributes. It is also possible that employed women's greater freedom of choice implies that they are more qualified because of selection or self-selection in terms of agentic qualities. That is, mainly those women who are agentic have chosen to work or have been specially selected to work (see also Footnote 8). An additional explanation stems from the finding that activities perceived to be voluntary rather than required are associated with more positive affect and higher involvement (Csikszentmihalyi \& Figurski, 1982). Therefore, the higher ratings of the agency (and communion) of employees who freely chose to work might be a consequence of the positive affect that has been observed to characterize this major portion of such individuals' lives.

\section{General Discussion}

According to our framework, social structure accounts for the content of stereotypes, or more exactly, the observed distribution of groups into various aspects of social structure underlies stereotypes. Although such an explanation may account for stereotypes about other subgroups within societies (e.g., races), we have confined our investigation to gender stereotypes by hypothesizing that the observed distribution of women and men into social roles underlies these stereotypes. In particular, our experiments investigated whether perceivers' beliefs about women and men stem from their previous observations of women and men in differing statuses within work hierarchies and in differing occupational roles. Because the content of gender stereotypes arises from perceivers' observations of people's activities and these activities are determined primarily by social roles, gender stereotypes (operationally defined as beliefs that certain attributes differentiate women and men; see Ashmore \& Del Boca, 1981) arise when women and men are observed typically to carry out different social roles.

Any theory of the content of gender stereotypes should account for the major perceived gender differences documented in past research-namely, the agentic qualities ascribed to men and the communal qualities ascribed to women. These differences should be accounted for by one or both of the major differences in the way women and men are distributed into social roles-namely, the concentration of women in lower positions in hierarchies of status and authority, and in the homemaker rather than the employee occupational role. In our research, only the homemaker-employee difference appeared to account for the subjects' beliefs that women are especially communal and men especially agentic. Although status differences did not account for these beliefs, it would be surprising, in view of the importance that sociologists have accorded to hierarchy as a fundamental aspect of social roles (e.g., Blau, 1964; Weber, 1947), if observed status differences did not underlie any beliefs about gender-differentiating traits and behaviors. On the contrary, status differences have been shown to account for the belief that women are more compliant than men (Eagly \& Wood, 1982). ${ }^{12}$

In documenting that occupational roles underlie belief in female communal qualities and male agentic qualities, our research has shown that beliefs about women resemble those about homemakers and that beliefs about men resemble those about employed persons. In addition, our research has shown that beliefs about what is typical of homemakers and employees override beliefs about what is typical of women and men, whereas the converse does not occur. Beliefs about what is typical of

\footnotetext{
12 Indeed, still other aspects of the distribution of men and women in society may affect beliefs about the sexes. For example, Kiesler (1975) suggested that because men outnumber women as successful achievers in many occupations, perceivers tend to evaluate an individual woman's achievements less favorably than an individual man's, even when their products are objectively equal. Perceivers' judgments of an individual's success may thus reflect the probability of success for persons of the individual's gender.
} 
women and men do not override beliefs about what is typical of homemakers and employees. ${ }^{13}$ Instead, except for the greater agency of female employees, women and men were perceived equivalently once their occupational role as homemaker or employee was specified. The underlying reason that occupational role is more important than sex in determining beliefs about communal and agentic characteristics is that stereotypes concerning these qualities have become associated with the sexes mainly because sex has been observed to covary with occupational role.

Although the finding that female employees are perceived as more agentic than their male counterparts was initially serendipitous, it is compatible with our social-structural perspective if it is interpreted in terms of perceived choice. The perception that employed women are likely to be employed by choice arises not only from perceivers' observations that women (and not men) are homemakers but also from their belief that women's primary obligation is to the domestic role, a belief documented by public opinion research (e.g., Mason, 1973; Mason, Czajka, \& Arber, 1976). Because traditionally the role of homemaker did not include any obligation to seek employment outside the home, employment tends to be regarded as an optional or freely chosen aspect of married women's lives. Therefore, even the perception of employed women as more agentic than employed men reflects previous observations of women's and men's different distributions into (and obligations in relation to) domestic and paid employment roles.

\section{Relation to Research on Cognitive Bases of Stereotyping}

Our research has implications for several aspects of stereotyping that have been examined recently in the research literature on social cognition. One highly relevant analysis has treated sex stereotypes as prior probabilities in a Bayesian model (Locksley, Borgida, Brekke, \& Hepburn, 1980; Locksley, Hepburn, \& Ortiz, 1982). Locksley and her colleagues found perceived sex differences in a target person's assertiveness only when subjects did not have diagnostic, individuating information about the target's previous levels of assertive- ness. This information caused the prior probabilities of women's and men's assertiveness to be revised. Similarly, in our research, even extremely general information about a person's employment status caused subjects to revise their estimates of women's and men's communal and agentic qualities.

Our findings, however, highlight the incompleteness of the Bayesian analysis, which does not explain why stereotypes have certain content, even though it does model a process by which past behavior or other characteristics that are believed to predict future behavior override information about sex. To account parsimoniously for the content of gender stereotypes, an investigator must find a behavioral or personal attribute that is diagnostic of the particular set of attributes believed to characterize women and men-namely, the strong communal and weak agentic tendencies ascribed to women and the weak communal and strong agentic tendencies ascribed to men. To explain these beliefs, an attribute must (a) differentiate the sexes and (b) relate to perceived agency and communion in opposite directions. As we have shown, these criteria are fulfilled by the occupational roles of homemaker and employee. Yet we have shown that one's position in hierarchies of status and authority does not meet these requirements.

Although most social cognition research has little power to account for the content of stereotypes, research on "illusory correlation" (e.g., Hamilton, 1981; Hamilton \& Gifford, 1976) pertains to content. It has shown that minority group members may be perceived to have characteristics with low probability of occurrence merely because the group members and such characteristics are both rare and therefore distinctive. In our research women constitute minorities in some social roles (e.g., as high-status employees), as do men in other social roles (e.g., as homemakers). Neverthe-

\footnotetext{
${ }^{13}$ Deaux and Lewis (in press) have also reported that role information is more important than sex in determining beliefs about women and men, although their role descriptions included more than occupational cues (e.g., the masculine role was described as "head of the household, financial provider, a leader, and responsible for household repairs").
} 
less, despite their rarity, such women and men appear to be assigned primarily the attributes that correspond to the roles they occupy.

Our research also relates to the issue of whether there is a basic level of categorization that people commonly use in representing other people and ascribing attributes to them (Brewer, Dull, \& Lui, 1981; Cantor \& Mischel, 1979; Taylor, 1981). In particular, categorizations at this basic level are hypothesized to maximize the richness, differentiation, and vividness of subjects' perceptions of people. Using such criteria, Cantor and Mischel (1979) concluded that categorization at the level of social roles or "persona" is basic in person perception. It is notable that the research reported in the present article and our earlier research on beliefs about social influence (Eagly \& Wood, 1982) point to the importance of categorizations at the level of social roles (i.e., occupation and hierarchical status), which are highly diagnostic of people's traits and abilities. One's sex can be considered less basic than roles because it functions as a cue that, due to its previous association with social roles, provides indirect access to occupation and hierarchical status.

Finally, our framework is not inconsistent with the idea popular in the social cognition literature that stereotypes function as prototypes (e.g., Cantor \& Mischel, 1979) or schemata (e.g., Taylor \& Crocker, 1981). Our claim that observations of social roles underlie gender stereotypes is not meant to imply that the stimulus person's social role is ordinarily retrieved for perceivers to infer her or his attributes. Instead, perceivers' prototype or schema of a typical woman or man is retrieved, and judgments are made in terms of the personal attributes already associated with it. Because people's activities are determined primarily by their social roles, the prototypes or schemata that perceivers possess of woman and man consist largely of attributes that covary with the role assignments of women and men. Therefore, our analysis primarily elaborates the process by which stereotypes have acquired particular content rather than the processes that occur when stereotypes are used to make judgments. Yet our analysis includes the important point that the use of gender stereotypes is under the control of cues that carry role information because of the origin of these stereotypes in observed variation in role assignments. Gender stereotypes are not applied when typical role arrangements are invalidated by these cues.

\section{Conclusion}

To turn from issues of cognitive mediation toward more general issues addressed in the stereotyping literature, we note that our analysis bears on the classic "kernel-of-truth" question pertaining to the validity of stereotypes. In assuming that stereotypes validly represent the social structure and division of labor in a society, our approach is consistent with that of other investigators who have implicated these factors as the kernel of truth of ethnic stereotypes (Brewer \& Campbell, 1976) and gender stereotypes (Williams \& Best, 1982). As such, our approach deviates from psychologists' more typical assumptions that stereotypes stem from psychological factors such as perceivers' distortions (e.g., Katz \& Braly, 1933; Lippmann, 1922) and biases inherent in perceivers' cognitive processing (e.g., Hamilton, 1979). However, the kernel-of-truth question is considerably broader than our social structural hypotheses, and as Brigham (1971), Campbell (1967), and others have noted, there is ample reason to believe that stereotypes both represent and distort reality. Our research, by relating stereotypes to perceived distributions into social roles, provides a promising avenue for addressing the kernelof-truth question.

This kernel-of-truth issue raises the question of whether the various attributes associated with social roles reflect ingrained personality traits and abilities characteristic of the typical occupants of the roles. In relation to homemaker and employee roles, for example, one may wonder whether girls are socialized to acquire communal traits and boys to acquire agentic traits, with the result that women as a group are more suited to perceivers' concept of the homemaker role and men as a group to perceivers' concept of the employee role. Although we believe that socializing agents tend to prepare girls and boys for the social roles that they believe these girls and boys will probably occupy as adults (Eagly, 1983), our 
theory of stereotypes does not address these issues of how people are prepared for roles and recruited into them. According to our framework, the proximal cause of gender stereotypes is the differing distributions of women and men into social roles, whatever the causation that lies behind these differing distributions.

We also note that our findings have some implications for the issue of gender equality. The gender or "sex role" stereotypes that psychologists have made famous and enshrined in their theories about gender and the methods of gender research appear to be eradicated and even partly reversed by information as general and basic as the fact that the persons being judged are employed. A literal interpretation of our findings suggests that employed women, who constitute about half of American women (U.S. Department of Labor, 1980), are probably not ordinarily perceived in terms of the female stereotype of low agency and high communion, because it is usually quite salient to an employed woman's friends, associates, and family members that she is employed. Yet it is no doubt incorrect to think that employed women escape the traditional female stereotype altogether, because we do not fully understand the conditions under which people apply occupational stereotypes in preference to gender stereotypes. It is very likely that there are contexts in which an employed woman is perceived traditionally, even by people who know that she is employed.

It is also important to note that the stereotypes we obtained of employees do not portray women and men equally. Instead, these stereotypes favor the formerly excluded group: Employed women are perceived as more agentic than employed men (even though women are believed to have lower wages). Yet it should be kept in mind that the source of the extra agency appears to be the belief that women have freely chosen to be employed. Free choice is, of course, absent for many women, a fact acknowledged by our respondents in their estimates of the likelihood that employed women have freedom of choice. Enhanced agency would be ascribed mainly to relatively affluent, married women, because they could most plausibly be regarded as having freely chosen to enter the paid work force.
Another implication of our idea that social structure underlies beliefs about gender is that change in these beliefs probably must await social change. Our theory and findings suggest that gender stereotypes-the beliefs that women in general differ from men in generalwill not disappear until people divide social roles equally, that is, until child care and household responsibilities are shared equally by women and men and the responsibility to be employed outside the home is borne equally. Interventions designed to affect ideas about gender through education and exposure to the media (e.g., ensuring that textbooks have nonsexist portrayals of women and men) would, of course, have some impact in terms of our theory because beliefs about the distribution of people into social roles derive from indirect sources such as textbook portrayals as well as from direct experience. Yet daily life provides abundant direct experience with women and men. Therefore, efforts to remove gender stereotypes educationally may have relatively little impact, compared with actual changes in the distribution of the sexes into social roles.

\section{References}

Abramson, P. R., Goldberg, P. A., Greenberg, J. H., \& Abramson, L. M. (1977). The talking platypus phenomenon: Competency ratings as a function of sex and professional status. Psychology of Women Quarterly, 2, 114-124.

Ashmore, R. D., \& Del Boca, F. K. (1981). Conceptual approaches to stereotypes and stereotyping. In D. Hamilton (Ed.), Cognitive processes in stereotyping and intergroup behavior (pp. 1-35). Hillsdale, NJ: Erlbaum.

Bakan, D. (1966). The duality of human existence: An essay on psychology and religion. Chicago: Rand McNally.

Bem, S. L. (1974). The measurement of psychological androgyny. Journal of Consulting and Clinical Psychology, 42, 155-162.

Bishop, Y. M. M., Fienberg, S. E., \& Holland, P. W. (1975). Discrete multivariate analysis: Theory and practice. Cambridge, MA: MIT Press.

Blau, P. (1964). Exchange and power in social life. New York: Wiley.

Block, J. H. (1973). Conceptions of sex roles: Some crosscultural and longitudinal perspectives. American Psychologist, 28, 512-526.

Blood, R. O., Jr., \& Wolfe, D. M. (1960). Husbands and wives: The dynamics of married living. Glencoe, IL: Free Press.

Brewer, M. B. (1979). In-group bias in the minimal intergroup situation: A cognitive-motivational analysis. Psychological Bulletin, 86, 307-324. 
Brewer, M. B., \& Campbell, D. T. (1976). Ethnocentrism and intergroup attitudes: East African evidence. New York: Sage.

Brewer, M. B., Dull, V., \& Lui, L. (1981). Perceptions of the elderly: Stereotypes as prototypes. Journal of Personality and Social Psychology, 41, 656-670.

Brigham, J. (1971). Ethnic stereotypes. Psychological Bulletin, 76, 15-38.

Broverman, I. K., Vogel, S. R., Broverman, D. M., Clarkson, F. E., \& Rosenkrantz, P. S. (1972). Sex-role stereotypes: A current appraisal. Journal of Social Issues, 28, 59-78.

Brown, L. K. (1979). Women and business management. Signs, 5, 266-288.

Campbell, D. T. (1967). Stereotypes and the perception of group differences. American Psychologist, 22, 817829.

Cantor, N., \& Mischel, W. (1979). Prototypes in person perception. Advances in Experimental Social Psychology, $12,3-52$.

Clifton, A. K., McGrath, D., \& Wick, B. (1976). Stereotypes of women: A single category? Sex Roles, 2, 135148.

Cohen, J. (1977). Statistical power analysis for the behavioral sciences (2nd ed.). New York: Academic Press.

Cronbach, L. J. (1951). Coefficient alpha and the internal structure of tests. Psychometrika, 16, 297-334.

Csikszentmihalyi, M., \& Figurski, T. J. (1982). Self-awareness and aversive experience in everyday life. Journal of Personality, 50, 15-28.

Davis, J. A. (1974). Hierarchical models for significance tests in multivariate contingency tables: An exegesis of Goodman's recent papers. In H. L. Costner (Ed.), Sociological methodology, 1973-74 (pp. 189-231). San Francisco: Jossey Bass.

Deaux, K., \& Lewis, L. L. (in press). The structure of gender stereotypes: Interrelationships among components and gender label. Journal of Personality and Social Psychology.

Eagly, A. H. (1983). Gender and social influence: A social psychological analysis. American Psychologist, 38, 971981 .

Eagly, A. H., \& Wood, W. (1982). Inferred sex differences in status as a determinant of gender stereotypes about social influence. Journal of Personality and Social Psychology, 43, 915-928.

England, P. (1979). Women and occupational prestige: A case of vacuous sex equality. Signs, 5, 252-265.

Feldman, J. M. (1972). Stimulus characteristics and subject prejudice as determinants of stereotype attribution. Journal of Personality and Social Psychology, 21, 333340.

Gillespie, D. L. (1971). Who has the power? The marital struggle. Journal of Marriage and the Family, 33, 445458.

Hamilton, D. L. (1979). A cognitive-attributional analysis of stereotyping. Advances in Experimental Social Psychology, 12, 53-84.

Hamilton, D. L. (1981). lllusory correlation as a basis for stereotyping. In D. Hamilton (Ed.), Cognitive processes in stereotyping and intergroup behavior (pp. 115-144). Hillsdale, NJ: Erlbaum.
Hamilton, D. L., \& Gifford, R. K. (1976). Illusory correlation in interpersonal perception: $A$ cognitive basis of stereotypic judgments. Journal of Experimental Social Psychology, 12, 392-407.

Hartmann, H. I. (1981). The family as the locus of gender, class, and political struggle: The example of housework. Signs, 6, 366-394.

Jones, E. E., \& Davis, K. E. (1965). From acts to dispositions: The attribution process in person perception. Advances in Experimental Social Psychology, 2, 219266.

Kanter, R. M. (1977). Men and women of the corporation. New York: Basic Books.

Katz, D., \& Braly, K. W. (1933). Racial stereotypes of one hundred college students. Journal of Abnormal and Social Psychology, 28, 280-290.

Kiesler, S. B. (1975). Actuarial prejudice toward women and its implications. Journal of Applied Social Psychology, 5, 201-216.

Lippmann, W. (1922). Public opinion. New York: Harcourt, Brace.

Locksley, A., Borgida, E., Brekke, N., \& Hepburn, C. (1980). Sex stereotypes and social judgment. Journal of Personality and Social Psychology, 39, 821-831.

Locksley, A., Hepburn, C., \& Ortiz, V. (1982). Social stereotypes and judgments of individuals: An instance of the base-rate fallacy. Journal of Experimental Social Psychology, 18, 23-42.

Manis, M. (1971). Context effects in communication: Determinants of verbal output and referential decoding. In M. H. Appley (Ed.), Adaptation-level theory (pp. 237255). New York: Academic Press.

Mason, K. O. (1973). Studying change in sex-role definitions via attitude data. Proceedings of American Statistical Association, Social Statistics Section, 138-141.

Mason, K. O., Czajka, J. L., \& Arber, S. (1976). Change in U.S. women's sex-role attitudes, 1964-1974. American Sociological Review, 41, 573-596.

Mennerick, L. A. (1975). Organizational structuring of sex roles in a non-stereotyped industry. Administrative Science Quarterly, 20, 570-586.

Park, B., \& Rothbart, M. (1982). Perception of out-group homogeneity and levels of social categorization: Memory for the subordinate attributes in in-group and out-group members. Journal of Personality and Social Psychology, 42, 1051-1068.

Parsons, T. (1955). Family structure and socialization of the child. In T. Parsons \& R. F. Bales (Eds.), Family: Socialization and interaction process (pp. 35-131). Glencoe, IL: Free Press.

Scanzoni, J. (1982). Sexual bargaining: Power politics in the American marriage (2nd ed.). Chicago: University of Chicago Press.

Smedley, J. W., \& Bayton, J. A. (1978). Evaluative raceclass stereotypes by race and perceived class of subjects. Journal of Personality and Social Psychology, 36, 530535.

Spence, J. T., \& Helmreich, R. L. (1978). Masculinity \& femininity: Their psychological dimensions, correlates, $\&$ antecedents. Austin: University of Texas Press.

Tajfel, H. (1981). Human groups and social categories. New York: Cambridge University Press. 
Taylor, S. E. (1981). A categorization approach to stereotyping. In D. Hamilton (Ed.), Cognitive processes in stereotyping and intergroup behavior (pp. 83-114). Hillsdale, NJ: Erlbaum.

Taylor, S. E., \& Crocker, J. (1981). Schematic bases of social information processing. In E. T. Higgins, C. P. Herman, \& M. P. Zanna (Eds.), Social cognition: The Ontario symposium (Vol. 1, pp. 89-134). Hillsdale, NJ: Erlbaum.

Taylor, S. E., Fiske, S. T., Etcoff, N. L., \& Ruderman, A. J. (1978). Categorical and contextual bases of person memory and stereotyping. Journal of Personality and Social Psychology, 36, 778-793.

Taynor, J., \& Deaux, K. (1973). When women are more deserving than men: Equity, attribution, and perceived sex differences. Journal of Personality and Social Psychology, 28, 360-367.

Triandis, H. C. (1977). Interpersonal behavior. Monterey, CA: Brooks/Cole.
Upshaw, H. S. (1969). The personal reference scale: An approach to social judgment. Advances in Experimental Social Psychology, 4, 315-371.

U.S. Department of Labor, Bureau of Labor Statistics. (1980). Perspectives on working women: $A$ databook (Bulletin 2080). Washington, DC: Government Printing Office.

Weber, M. (1947). The theory of social and economic organization. Glencoe, IL: Free Press.

Williams, J. E., \& Best, D. L. (1982). Measuring sex stereotypes: A thirty-nation study. Beverly Hills, CA: Sage.

Zuckerman, M. (1979). Attribution of success and failure revisited, or: The motivational bias is alive and well in attribution theory. Journal of Personality, 47, 245-287.

Received March 28, 1983

Revision received November 9, 1983

\title{
New Journal on Aging: Call for Nominations
}

By action of APA's Publications and Communications Board and Council of Representatives, the APA is publishing a quarterly journal called Psychology and Aging, the first issue of which will appear in 1985. Psychology and Aging will contain original articles on adult development and aging. The articles may be reports of research or applications of research, and they may be biobehavioral, psychosocial, educational, methodological, clinical, applied, or experimental (laboratory, field, or naturalistic) studies. For more information about the new journal, see the November 1983 issue of the APA Monitor.

Nominations for the editor of Psychology and Aging are now open. Candidates must be members of APA and should be available to start receiving manuscripts in mid-1984 to prepare for issues published in 1985. To nominate candidates, prepare a statement of one page or less in support of each candidate. Submit nominations no later than April 2, 1984, to:

\author{
Martha A. Storandt \\ Department of Psychology \\ Box 1125 \\ Washington University \\ St. Louis, Missouri 63130 \\ (314) 889-6508
}

